\title{
Investigação criminal à luz da Lei 9.034/95: a atuação de agentes infiltrados e suas repercussões penais
}

Jayme José de Souza Fllho ${ }^{1}$

\section{Resumo}

\begin{abstract}
A Lei 9.034 de 03 de maio de 1995 dispõe sobre a utilização de meios operacionais para a prevenção e repressão de ações praticadas por organizações criminosas. Sofreu alteração pela Lei 10.217 de 11 de abril de 2001, que inseriu no ordenamento jurídico brasileiro a técnica de infiltração de agentes como instrumento de combate a tais organizações. Prevê que agentes de polícia ou de inteligência, em qualquer fase de persecução criminal, desde que autorizados judicialmente, possam inserir-se em grupos criminosos agindo dissimuladamente como parte integrante destes, visando obter informações e provas para atingirem o seu desmantelamento. É inadmissível a atuação de particular como agente infiltrado. É omissa a legislação acerca dos limites e sucinta com relação aos requisitos que devem ser impostos para o exercício deste método investigativo. Silenciou-se ainda a respeito das responsabilidades penais do agente infiltrado no exercício de suas atividades, assim, eventuais responsabilidades devem ser resolvidas no campo da Teoria do Delito, previstas na Parte Geral do Código Penal. Difere $o$ agente infiltrado do agente provocador, onde o primeiro age constantemente de forma passiva, coletando dados, enquanto que o segundo age de forma ativa, instigando o alvo (suspeito) à prática de ilícitos. As provas obtidas pelo agente infiltrado e seu testemunho são legítimos a instruírem inquérito policial e ação penal competente.
\end{abstract}

Palavras Chave: Crime Organizado; Organizações Criminosas; Agente Infiltrado; Investigação Criminal; Infiltração; Prova; Lei 9.034/95.

\section{Introdução}

A criminalidade inserida na sociedade contemporânea beneficia-se do uso de instrumentos organizacionais e materiais desenvolvidos pelo progresso da humanidade visando-os para seus fins ilícitos, portanto, não pode o aparelho estatal ficar inerte a estas transformações, devendo buscar meios de repressão a este tipo de atividade criminal conforme sua evolução.

É neste cenário moderno em que se encontram as Organizações Criminosas, entidades organizadas com pluralidade de agentes, estruturação hierárquica, divisão de

1 Especialista em Direito e Processo Penal pela Universidade Estadual de Londrina - UEL. Artigo baseado em trabalho de conclusão de curso orientado pelo Prof. Ms. Eduardo Diniz Neto. 
funções, elevado poderio econômico e de corrupção, alto grau de intimidação, influência em ações políticas e atividades em níveis locais e internacionais.

No intuito de prevenir e coibir as ações destas organizações criminosas o legislador pátrio inseriu em nosso ordenamento jurídico a Lei 9.034/95 a qual dispõe sobre a utilização de meios operacionais para este intento, alterada seis anos depois pela Lei 10.217/01, que sofre ainda hoje crítica por parte da doutrina com relação a sua aplicabilidade e legalidade de alguns de seus dispositivos.

Previu sucintamente em citada legislação, de forma inédita no ordenamento pátrio, a figura do agente infiltrado, que consiste na inserção de um agente do Estado no seio de uma organização criminosa, agindo dissimuladamente como parte integrante desta, visando obter informações e provas que resultem no seu desmantelamento.

O presente trabalho pretende focar a investigação criminal com base na figura do agente infiltrado, realizando uma análise de sua origem, forma procedimental e suas repercussões no âmbito jurídico, com o intuito de trazer luz ao tema valendo-se de preceitos e princípios do Direito Constitucional, Direito Processual Penal, Direito Penal e Hermenêutica Jurídica.

\section{Organizações criminosas}

As atuações de organizações criminosas podem ser constatadas em diversos países do mundo, possuindo entre elas algumas diversidades impostas pela cultura local e pelo objeto explorado pela organização.

Historicamente, algumas organizações tornaram-se mundialmente conhecidas, como é o caso das Tríades Chinesas, Yakuza (Japão), Máfia italiana e posteriormente ítaloamericana, Cartéis do narcotráfico colombiano, entre outras. Sua origem é antiga sendo de difícil precisão, uma vez que trata-se de grupos que agem à margem da sociedade constituída, entretanto, algumas características quase sempre estão presentes no início de suas criações, como explica Eduardo Araújo da Silva:

A maioria teve como nascedouro movimentos populares, o que facilitou sobremaneira sua aceitação na comunidade local, assim como o recrutamento de voluntários para o exercício de suas posteriores atividades ilícitas; muitas delas passaram a atuar no vácuo de algumas proibições estatais (exploração da prostituição, jogos de azar, venda de entorpecentes e de armas sofisticadas); 
contaram com a conivência de agentes do Estado para o desenvolvimento de suas atividades ilícitas; e impuseram sua lei pelo emprego da ameaça e violência, voltada, sobretudo para delatores e integrantes de grupos concorrentes. (SILVA, 2003, p. 27).

A legislação brasileira especificamente não definiu o que vem a ser organização criminosa, mas a doutrina e jurisprudência discursam sobre o assunto, apontando como principais características destas organizações: acumulação de poder econômico, hierarquia estrutural ou piramidal, planejamento empresarial com divisão funcional de atividades visando o fim de lucro, delimitação de território e áreas de atuação, conexões com o poder público/político resultantes num alto grau de corrupção, acesso a recursos tecnológicos modernos, facilidade no recrutamento de pessoal, assistencialismo junto a comunidade local ou aos seus membros e familiares destes, alto poder de intimidação, manutenção de relações locais, regionais e internacionais com outras organizações criminosas e elevado grau de violência para seus delatores e de suas famílias ou ainda para grupos rivais.

Entretanto, com o advento recente do Decreto n.o 5.015/04, que promulga a Convenção das Nações Unidas contra o Crime Organizado Transnacional, também conhecida como Convenção de Palermo, entendemos que o referido assunto envolvendo organizações criminosas transnacionais já não deve mais suscitar dúvidas, uma vez que no Artigo 2 , " $a$ " de referida Convenção indica que entende-se por: “' 'Grupo criminoso organizado' - grupo estruturado de três ou mais pessoas, existente há algum tempo e atuando concertadamente com o propósito de cometer uma ou mais infrações graves ou enunciadas na presente Convenção, com a intenção de obter, direta ou indiretamente, um benefício econômico ou outro benefício material;" e em sua alínea "b" prescreve que entende-se por: " "Infração grave' - ato que constitua infração punível com uma pena de privação de liberdade, cujo máximo não seja inferior a quatro anos ou com pena superior;".

\section{Legislação}

Na sua origem, a Lei 9.034/95 em seu art. 1. fazia menção apenas as expressões de quadrilha ou bando, somente com o advento da Lei 10.217/01 que foram acrescidas as terminologias de organizações ou associações criminosas de qualquer tipo. 
A Lei 9.034/95 previa em seu projeto originário no inciso I do art. 2.ํ, como procedimento de investigação e formação de prova: "a infiltração de agentes da polícia especializada em quadrilhas ou bandos, vedada qualquer co-participação delituosa, exceção feita ao artigo 288, do Decreto-lei 2.848, de 7 de dezembro de 1940-Código Penal, de cuja ação se preexclui, no caso a antijuridicidade", o referido inciso fora vetado pela Presidência da República principalmente pelo fato de não contemplar a necessidade de autorização judicial para a infiltração de agentes, mas previa de forma acertada a regulamentação sobre a responsabilidade penal por parte do agente infiltrado no exercício de sua atividade, considerando neste caso a ocorrência de uma exclusão de antijuridicidade. Verifica-se ainda que somente o agente de polícia poderia realizar a infiltração.

Tal regulamentação de infiltração de agentes deu-se tão somente com a Lei 10.217/01 que ampliou os grupos criminosos previsto no art. 1.ㅇ, bem como, inseriu a participação de agentes de inteligência alternativamente aos agentes de polícia como executores da infiltração, previu ainda a necessidade de autorização judicial para a realização deste tipo de procedimento, conforme inciso $V$ do art. 2.‥ Entretanto, de maneira prejudicial ao esclarecimento da matéria, ficou omissa no âmbito da responsabilidade penal do agente durante suas atividades.

Afora a lei de combate as organizações criminosas a Lei 10.409, de 11 de janeiro de 2002, conhecida como a Nova Lei de Tóxicos, também previu em seu art. 33, I a figura do agente infiltrado, permitindo nesta legislação a prática da infiltração tão somente por policiais, neste caso, além da autorização judicial, tornou-se necessário a oitiva do Ministério Público.

\section{Agente infiltrado e características da infiltração}

A figura do agente infiltrado inserido na legislação pátria tem sua origem no "undercover" norte-americano, ou seja, o Brasil seguiu uma tendência internacional no combate ao crime organizado. Nos EUA as principais técnicas de investigação com relação ao combate às organizações criminosas são: a operação undercover, o uso de informantes e a vigilância eletrônica.

Entende-se por "undercover" o agente estatal que de forma dissimulada ingressa na organização investigada para colher informações que visem o seu desmantelamento, por 86

ReVista de Direito Público, Londrina, v. 1, N. 2, P. 83-96, MAIO/Ago. 2006. 
meio da identificação de seus integrantes e coleta de elementos probatórios que venham a subsidiar a instrução criminal. Nesse caminho países como México, Argentina, Espanha, Chile, Portugal, Alemanha e França já possuem a matéria regulamentada em seus ordenamentos positivos.

No Brasil valendo-se de uma interpretação sistêmica da legislação em estudo, podemos definir o agente infiltrado, como o servidor público pertencente aos órgãos policiais ou a órgãos estatais constituídos com setores de inteligência investigativa, incumbido de inserir-se em quadrilha ou bando ou organizações ou associações criminosas de qualquer tipo, com o intuito de proceder diligências investigativas que promovam a sua repressão.

Deste modo, o agente infiltrado busca informações que revelem quem são os integrantes de tais grupos criminosos, suas fontes recursais, seus locais de atuação, bem como suas relações internas e externas, ou seja, seu modus operandi, visando ao final de sua intervenção chegar a uma conclusão investigativa ou à obtenção de provas a serem demonstradas em procedimento próprio (judicial ou administrativo).

Prevê o inciso $V$ do art. 2. da Lei 9.034/95 que a infiltração nas organizações criminosas se dará por agentes de polícia ou de inteligência. Por agentes de polícia, entendese todos aqueles elencados no art. 144 da Constituição Federal, entretanto, faz-se necessário demonstrar neste momento a distinção com relação às polícias judiciárias (civil e federal) com as demais polícias militares, pois estas últimas somente poderão valer-se do instituto do agente infiltrado quando funcionarem como polícias investigativas apurando a atuação de organizações criminosas em crimes militares.

Com relação aos agentes de inteligência, Denílson Feitoza Pacheco, em estudo sobre atividades de inteligência e processo penal ensina que:

Como a Lei federal 9.883/1999 instituiu o Sistema Brasileiro de Inteligência e o Decreto federal 3.695/2000 criou o Subsistema de Inteligência de Segurança Pública, isso implica que o agente de inteligência deve ser de um órgão público formalmente constituído como órgão de inteligência. Assim, podem ser utilizados os agentes de inteligência da Agência Brasileira de Inteligência (ABIN), do Exército, da Marinha, da Aeronáutica, do Ministério da Defesa, das Administrações Penitenciárias, das Secretarias Estaduais da Fazenda, Secretaria da Receita Federal e, enfim, de outros órgãos públicos que tenham formalmente constituído sua unidade de inteligência e vinculado seu servidor a ela como agente de inteligência. Observe que a Lei 9.034/1995 estabelece que a pessoa infiltrada deve ser agente 
de polícia 'ou' agente de inteligência, sem restringir a instituição à qual pertence o agente de inteligência. ${ }^{2}$

Tal posicionamento, entretanto, não se encontra sedimentado pacificamente, primeiro porque no art. 2. da Lei 9.034/65 prevê a existência de uma persecução criminal, e não meramente administrativa como pode decorrer da atuação de agentes que não sejam pertences as polícias judiciárias (ou polícias milicianas no caso de crimes militares); segundo porque o art. 4. de referida lei, no capítulo destinado as disposições gerais versa: "Art. 4.ㅇ Os órgãos da polícia judiciária estruturarão setores e equipes de policiais especializados no combate a ação praticada por organizações criminosas."(nosso grifo). Ora, se a polícia judiciária que tem a incumbência prevista constitucionalmente de realizar a apuração das infrações penais (exceto as militares) é a única citada para estruturar-se na apuração destes tipos criminais, qual a motivação de outros órgãos não terem sido elencados, uma vez que não são institucionalizadas especificamente para a apuração de delitos. Há ainda que ressaltar, um outro ponto de vista com base na proteção de direitos fundamentais assegurados na Constituição Federal, onde temos nas argüições de Luiz Otávio de Oliveira Rocha quando indica que:

\begin{abstract}
Assim, é de duvidosa constitucionalidade a permissão contida na 10.217 de atuação de 'agentes de inteligência' (aludindo a agentes de serviços de informação) como 'infiltrados', na medida em que a tais agentes não são em regra cometidas funções de polícia judiciária e, desse modo, não estão legitimados a coletar provas voltadas a futura utilização em processo penal, única causa legítima capaz de fundamentar as violações à intimidade e outros direitos fundamentais que implica a atividade de infiltração. Porém, se considerada a inserção dos requisitos legais da autorização judicial e da existência de investigação formal em curso, se pode afirmar que não haverá incompatibilidade constitucional na atuação de "agentes de inteligência", sempre que suas funções investigatórias estiverem previstas em lei, a qual tenha instituído procedimento para a formalização do respectivo conteúdo. O resultado de investigações que tais poderá, então, ser legitimamente aproveitado pelos órgãos de polícia judiciária. ${ }^{3}$
\end{abstract}

Se a matéria relativa a quem pode exercitar as atividades de agente infiltrado já se apresenta com certa controvérsia entre a doutrina nacional, podemos acertadamente

2 PACHECO, Denilson Feitoza. Atividades de inteligência e processo penal. In: IV JORNADA JURÍDICA DA JUSTIÇA MILITAR DA UNIÃO - AUDITORIA DA 4a CJM, 30 set. 2005, Juiz de Fora/MG. Disponível em: $<$ www.militar.com.br/legisl/artdireitomilitar/ano2005/denilsonfeitozapacheco/atividadedeinteligencia.htm $>$ Acesso em: 19 fev. 2006.

3 ROCHA, Luiz Otávio de Oliveira. Agente infiltrado: inovação da Lei 10.217/2001. Disponível em: $<$ http://www.esmp.sp.gov.br/publicacoes/revista_1.pdf>. Acesso em: 10 jan. 2006. 
Investigação criminal à luz da Lei 9.034/95: a atuação de agentes infiltrados e suas repercussões penais

vislumbrar que é inadmissível dentro do ordenamento brasileiro, a aceitação de particulares agindo como agentes infiltrados por completa falta de previsão legal, que se assim previsse estaria fadada ao insucesso pelas conseqüências jurídicas que tal fato acarretaria para o particular e para o próprio Estado, principalmente no tocante as responsabilidades penais que o Estado teria no caso de algum cometimento de ilícito por parte do particular quando do exercício das atividades de agente infiltrado.

A infiltração de agentes deve assim possuir algumas características elementares como: a dissimulação, o engano e a interatividade, sem as quais inviabilizaria todo o intento investigativo. Em razão do risco iminente neste tipo de empreitada, o agente infiltrado deve ser alguém treinado especificamente para este tipo de ação, possuir falsa identidade e vida pregressa bem como uma equipe de apoio durante toda interação com o grupo criminoso, que além de prestar assistência, possibilite o encaminhamento das informações produzidas junto à autoridade competente.

Há uma diferenciação entre o agente infiltrado e o agente provocador: o agente provocador atua de forma a instigar o indivíduo a praticar uma ação delituosa, agindo assim de forma ativa, enquanto que o agente infiltrado para obter êxito na aplicação da responsabilidade penal face aos criminosos atua constantemente de forma passiva, acompanhando a ação delituosa já preexistente no grupo objeto de investigação. Isto porque, se agisse de forma a provocar a ação delituosa estaria desvirtuado de seu intento e não conseguiria juridicamente imputar o fato criminoso ao investigado, conforme melhor orientação doutrinária e jurisprudencial. ${ }^{4}$

\section{Requisitos para haver a infiltração de agentes}

A infiltração de agentes somente pode ser admitida como procedimentos investigatórios que versem sobre ilícitos decorrentes de ações praticadas por quadrilha ou bando ou organizações ou associações criminosas de qualquer tipo, conforme previsto no

\footnotetext{
4 “a figura do agente infiltrado é, pois, substancialmente diferente da do agente provocador. O agente provocador cria o próprio crime e o próprio criminoso, porque induz o suspeito à práticas de actos ilícitos, instigando-o e alimentando o crime, agindo nomeadamente, comprador ou fornecedor de bens ou serviços ilícitos. O agente infiltrado, por sua vez, através de sua actuação limita-se, apenas, a obter a confiança do suspeito(s), tornando-se aparentemente um deles para, como refere Manuel Augusto Alves Meireis, 'desta forma, ter acesso as informações, planos, processos, confidências...' que, de acordo com o seu plano constituirão as provas necessárias à condenação". (GONÇALVES, Fernando et al. Lei e crime: o agente infiltrado versus o agente provocador. Os princípios do processo penal. Coimbra: Almedina, 2001. p. 264)
} 
art. 1. da Lei 9.034/95. Neste sentido torna-se imperioso primeiramente identificar quais são e onde estão previstos tais coletividades criminosas.

Quadrilha ou bando estão previstos no art. 288 do Código Penal Brasileiro.

Associações criminosas encontram-se previstas em leis penais especiais como é o caso dos artigos 14 e 18, III da Lei 6.368/76 (Lei de Tóxicos), artigo 2. , III da Lei 2.889/56 (Lei de Genocídio), artigos 16 e 24 da Lei 7.170/83 (Lei de Segurança Nacional) e artigo 8.ㅇ da Lei 8.072/90 (Lei de Crimes Hediondos).

Por sua vez, tratando-se de organizações criminosas de caráter eminentemente nacional, torna-se necessário buscar seu entendimento nas ciências criminológicas que elencam suas características principais, conforme já discorrido no item 2 . Todavia sendo a organização criminosa de caráter transnacional, sua conceituação está prevista na Convenção de Palermo, ratificada pelo Decreto n.o 5.015/04.

Como requisito substancial à atuação deste meio operacional de investigação, prevê a Lei 9.034/95 alterada pela Lei 10.217/01, a necessidade de prévia autorização judicial, devendo dar-se de maneira circunstanciada e sigilosa.

Como circunstanciada, entendemos que a autorização deverá abranger alguns elementos norteadores da ação, seja com relação à identificação dos agentes infiltrados, seja com relação ao seu aspecto temporal de vigência, determinação (mesmo que sucinta) de qual grupo criminoso se pretende investigar, assim como seu principal objeto de incidência criminal (corrupção, crimes cibernéticos, tráfico de pessoas, etc.). Justifica-se a necessidade da autorização ser circunstanciada à medida que possibilita uma maior segurança jurídica na aplicação da lei penal junto ao meio social.

O sigilo por sua vez, é imprescindível para a eficiência deste instituto, bem como, para a preservação da integridade física do agente, tratando-se a infiltração como método de eminente risco para o servidor operante.

De forma bastante sucinta a legislação não previu quem pode requerer a aplicação deste procedimento, se o Juiz pode ou não determina-la de ofício, se há a necessidade de dar-se ciência ao Ministério Público (em caso de não ser ele o autor do requerimento), quais os requisitos para seu deferimento, a quem deve ser dirigido o relatório investigativo e de que forma deverá sê-lo. 
Investigação criminal à luz da Lei 9.034/95: a atuação de agentes infiltrados e suas repercussões penais

Neste sentido, parte da doutrina nacional defende que por respeito às garantias do investigado, deverá ser adotado por analogia o procedimento previsto na Lei 9.296/96 que regulamenta a interceptação de comunicações telefônicas, fluxo de comunicações em sistemas de informática e telemática, entende seus defensores que tal aplicação é válida por orientar-se pelo Princípio da Proporcionalidade, tendo em vista que em ambos os casos são restringidos a garantia constitucional de direito à privacidade dos indivíduos investigados.(SILVA, 2003).

\section{Responsabilidade penal do agente infiltrado}

Matéria bastante controversa na doutrina nacional refere-se à responsabilidade penal do agente infiltrado. Comete ele algum delito no exercício de sua atividade ao fazer parte de um grupo criminoso elencado na lei? Não estaria ele, no mínimo, cometendo o crime capitulado no art. 288 do Código Penal Brasileiro? E se o agente infiltrado cometer algum outro delito que não seja o coletivo, estará ele acobertado por alguma excludente? Qual?

Tais indagações já foram suscitadas por Wilson Lavorenti, conforme se depreende:

Outra grande dificuldade para a adoção desta forma de atuação reside na celeuma que se cria quanto às condutas possíveis por parte do agente infiltrado, dado que, para sua aceitação e mantença em uma organização, necessariamente, estará contribuindo ou praticando ações penais. Em outras palavras, o Estado, para se ver livres de crimes, deveria permitir, por parte de seus agentes infiltrados, a prática de infrações, o que é no mínimo paradoxal. Por outro lado, nenhum policial estaria disposto a se infiltrar e responder pela prática de delitos praticados.(SILVA; LAVORENTI; GENOFRE, 2003, p. 242).

Toda ação investigativa exercida pelo Estado no combate a criminalidade tem por si só determinado grau de risco inerente à função, entretanto muito maior o risco será quanto mais próximo se encontrar do objeto investigado, principalmente se estiver diante de uma organização criminosa, nestes termos, para que seja viabilizada a atuação do agente infiltrado, deverá este servidor encontrar-se respaldado juridicamente quando realizar suas diligências.

Ademais, não assiste amparo lógico-jurídico criar-se uma lei permitindo uma conduta que é proibida por outra lei. 
Para responder estas e outras indagações, recorreremos aos elementos formadores da Teoria do Delito, principalmente no tocante as suas excludentes.

Vislumbrando o assunto em tela, Alberto Silva Franco, discorre que:

\begin{abstract}
Na doutrina discute-se a posição jurídica do agente infiltrado, afirmando alguns a licitude de seu procedimento por ter atuado no estrito cumprimento do seu dever ou no exercício regular de direito legal ou a carência de culpabilidade por obediência hierárquica a ordem não manifestamente ilegal. Já outros asseguram existir na hipótese escusa absolutória, o que implica o reconhecimento do fato criminoso, sem imposição de pena em virtude de uma postura políticocriminal.(FRANCO, 2002, p.586).
\end{abstract}

Para o enfretamento da questão, torna-se necessário inicialmente subdividirmos a responsabilidade penal do agente em duas situações distintas. A primeira diz respeito à participação do agente infiltrado no cerne de uma coletividade criminosa (quadrilha, bando, associação ou organização criminosa de qualquer tipo) sem cometer nenhum outro ato que importe em uma eventual prática delituosa. Nestas situações, não é possível a responsabilização do agente infiltrado pela prática de crimes de Quadrilha ou Bando (artigo 288 do (PB) ou qualquer outro crime associativo previsto na legislação penal extravagante, como os capitulados nos artigos 14 e 18, III da Lei 6.368/76 (Lei de Tóxicos), artigo 2.o , III da Lei 2.889/56 (Lei de Genocídio), artigos 16 e 24 da Lei 7.170/83 (Lei de Segurança Nacional) e artigo 8. da Lei 8.072/90 (Lei de Crimes Hediondos), isto porque, estará a ação do agente infiltrado em consonância com seu Exercício Regular de Direito (artigo 23, III do CPB), sendo esta uma causa de excludente da antijuridicidade. Uma vez que, o agente infiltrado assim procede autorizado judicialmente com base em uma norma permissiva (inciso $\mathrm{V}$ do artigo 2.ㅇ da Lei 9.034/95). Diferentemente ocorreria se agisse com base em uma norma impositiva, pois neste caso apesar de continuar amparado por uma excludente de antijuridicidade, melhor enquadramento ensejaria o Estrito Cumprimento do Dever Legal (artigo 23, III do (PB).

A segunda situação com enfrentamento de maior complexidade, diz respeito ao fato de o agente infiltrado encontrar-se em situação a qual tenha que cometer um ilícito para prosseguir no seu intento (obtenção de informações ou provas que visem o desmantelamento da organização) ou preservar sua integridade física que se encontre ameaçada pelo grupo criminoso. Notadamente tais casos devem decorrer somente de 
situações excepcionais sendo que, pela completa falta de previsão legal, dificilmente será pacificado seu entendimento. Em que pese divergências doutrinárias, cremos que a melhor resolução encontrar-se-ia no campo da culpabilidade, pois estaria o agente em face de uma Inexigibilidade de Conduta Diversa. Deste modo, existiria a ação delituosa, não sendo viável sua censurabilidade. Há neste caso uma dirimente supralegal, restando demonstrado uma situação anormal criada pelo exercício de uma função legítima e autorizada. Sendo a inexigibilidade de conduta diversa um verdadeiro princípio da culpabilidade, não torna-se coerente limitá-lo a previsão legal, sob pena da violação de seu maior princípio "nullum crime sine culpa".

No caso de condutas ilícitas praticadas pelo agente infiltrado que não esteja em situações extremadas ou onde não haja nenhum conflito entre bens jurídicos tutelados, ficará evidenciado um desvio e/ou excesso na conduta, devendo o servidor assim ser responsabilizado no âmbito administrativo e judicial.

Um outro posicionamento, de menor segurança jurídica, mas não menos importante, é o defendido por Eduardo Araújo da Silva, que busca no Princípio da

Proporcionalidade a elucidação para o tema:

A análise da proporcionalidade entre a conduta do policial infiltrado e o fim buscado pela investigação é o caminho a ser trilhado. Não se apresenta razoável, por exemplo, admitir que o policial possa matar pessoas na busca de elementos de prova para a apuração de crimes praticados contra a flora e a fauna.(SILVA, 2003, p. 90).

Pelo exposto, verifica-se que a complexidade apresentada pelo tema apresenta somente tornar-se-á pacificada quando o legislador explicitamente regular o assunto, assim como fizeram países como Estados Unidos, Argentina e Espanha. ${ }^{5}$

\section{Considerações finais}

A criminalidade avança concomitantemente ao progresso das civilizações, utilizando-se de todos recursos financeiros, tecnológicos e organizacionais disponíveis junto

ROCHA, Luiz Otávio de Oliveira. Agente infiltrado: inovação da Lei 10.217/2001. Disponível em: <http://www.esmp.sp.gov.br/publicacoes/revista_1.pdf>. Acesso em: 10 jan. 2006. 
ao meio social. Desta forma, para viabilizar a sua repressão, necessário se faz à criação de institutos e procedimentos investigativos e processuais adequados a sua evolução.

Neste sentido, numa tendência mundial, vislumbra-se a inserção de procedimentos como a colaboração processual, infiltração de agentes, ação controlada, interceptação de comunicações e ambiental, quebra de sigilos fiscais, bancário e financeiro, entre outros.

Como alguns destes procedimentos são formas de violações as garantias constitucionais como a privacidade e intimidade, a sua aplicação somente deve ocorrer quando restar demonstrado de forma robusta a sua necessidade.

No Brasil a Lei 9.034/95, alterada posteriormente pela Lei 10.217/01, veio instrumentalizar a forma de como o aparato estatal pode prevenir e reprimir as ações ilícitas praticadas por coletividades criminosas.

A referida legislação inovou ao prever a figura do agente infiltrado, sendo este um método operacional investigativo de grande valia na repressão criminal pretendida.

A infiltração de agentes é um procedimento previsto legalmente e quando for autorizada judicialmente a sua realização, as provas produzidas durante a sua execução serão válidas e legítimas a instruírem inquérito policial e ação penal.

Não pode o agente infiltrado instigar, induzir ou provocar a prática de ações ilícitas dentro da coletividade criminosa na qual esteja inserido, sob pena de passar a ser aquilo que a doutrina denomina de agente provocador, cujas provas obtidas não terão validade jurídica para responsabilizar criminalmente o autor do fato.

A autorização judicial além de ser sigilosa deverá ser sempre circunstanciada, delimitando com isso a atuação do agente infiltrado e por consequência garantindo segurança jurídica de sua aplicação junto à sociedade.

Somente o servidor público poderá atuar como agente infiltrado, sendo inadmissível ao Estado valer-se de particulares para a realização de infiltração em organizações criminosas.

Ao inserir-se em uma coletividade criminosa o agente infiltrado não comete o delito de quadrilha ou bando ou qualquer outro referente a organizações ou associações criminosas de qualquer tipo, porque estará a ação praticada pelo agente infiltrado em conformidade com o seu exercício regular de direito, sendo esta uma causa de exclusão de antijuridicidade. 
A legislação não contempla condutas típicas que podem ser praticadas pelo agente infiltrado durante o exercício de suas atividades, entretanto, se este se encontrar em situações extremadas e vier a praticar algum ilícito poderá o caso concreto encontrar resolução no campo da culpabilidade, verificando-se a exigibilidade ou não de conduta diversa, ou ainda ser resolvida em vista do princípio da proporcionalidade.

A legislação com relação aos requisitos procedimentais é sucinta, desta forma parte da doutrina entende que por analogia deve ser aplicado a Lei 9.296/06 que regulamenta a interceptação de comunicações telefônicas, fluxo de comunicações em sistemas de informática e telemática, porque em ambos os casos são restringidos a garantia constitucional de direito à privacidade dos indivíduos investigados.

Por fim, visando orientar melhor a aplicação da infiltração de agentes, urge complementação imediata por parte do legislador de maneira a regulamentar este método investigativo, não apenas orientado para a repressão de organizações criminosas e garantias individuais dos investigados, mas também com relação às garantias que o executor deste procedimento deve ter para si e sua família uma vez que se trata de função eminentemente de risco.

\section{Referências}

FRAGOSO, Heleno Cláudio. Lições de direito penal Parte geral. 4. ed. Rio de Janeiro: Forense, 1995.

FRANCO, Alberto Silva; STOCO, Rui. Leis penais especiais e sua interpretação jurisprudencial. São Paulo: Revista dos Tribunais, 2002.

GARCIA, Ismar Estulano. Procedimento policial: inquérito. Goiânia: AB-Editora, 2002.

GOMES, Luiz Flávio; CERVINI, Raúl. Crime organizado. 2 ed. São Paulo: Revista dos Tribunais, 1997.

GOMES FILHO, Antônio Magalhães. Direito à prova no processo penal. São Paulo: Revista dos Tribunais, 1997.

GONÇALVES, Fernando et al. Lei e crime: o agente infiltrado versus o agente provocador. Os princípios do processo penal. Coimbra: Almedina, 2001. 
JESUS, Damásio E, de. Código penal anotado. 10. ed. São Paulo: Saraiva, 2000.

MARQUES, José Frederico. Tratado de direito penal. Campinas: Bookseller, 1997. v. 1.

MIRABETE, Julio Fabrini. Código de processo penal interpretado. 4. ed. São Paulo: Atlas, 1999.

PACHECO, Denilson Feitoza. Atividades de inteligência e processo penal. In: IV JORNADA JURÍDICA DA JUSTIÇA MILITAR DA UNIÃO - AUDITORIA DA 4a CJM, 30 set. 2005, Juiz de Fora/MG. Disponível em: <www.militar.com.br/legisl/ artdireitomilitar/ ano2005/ denilsonfeitozapacheco/atividadedeinteligencia.htm>. Acesso em: 19 fev. 2006.

PRADO, Luiz Régis. Curso de direito penal brasileiro. São Paulo: Revista dos Tribunais, 1999. V. 1.

ROCHA, Luiz Otávio de Oliveira. Agente infiltrado: inovação da Lei 10.217/2001. Disponível em: <http://www.esmp.sp.gov.br/publicacoes/revista_1.pdf>. Acesso em: 10 jan. 2006.

SILVA, Eduardo Araújo da. Crime Organizado: procedimento probatório. São Paulo: Atlas, 2003.

SILVA, José Afonso da. Curso de direito constitucional positivo. 16. ed. São Paulo: Malheiros, 1999.

SILVA, José Geraldo da; LAVORENTI, Wilson; GENOFRE, Fabiano. Leis Penais Especiais Anotadas. 4. ed. Campinas: Millennium, 2003.

TENÓRIO, Igor; LOPES, Inácio Carlos Dias. Crime organizado. Brasília: Consultex, 1995.

TOURINHO FILHO, Fernando da Costa. Processo penal. 15 ed. São Paulo: Saraiva, 1994. v. 1.

ZAFFARONI, Eugenio Raúl; PIERANGELLI, José Enrique. Manual de direito penal brasileiro. São Paulo: Revista dos Tribunais, 1997. 